\title{
Generation of porcine fibroblasts overexpressing 11ß-HSD1 with adipose tissue-specific aP2 promoter as a porcine model of metabolic syndrome
}

\author{
EUI-MAN JUNG ${ }^{1}$, BEUM-SOO AN ${ }^{2}$, YU-KYUNG KIM ${ }^{3}$, YOUNG-HEE JEONG ${ }^{3}$, \\ WOO-SUK HWANG ${ }^{3}$ and EUI-BAE JEUNG ${ }^{1}$
}

\author{
${ }^{1}$ Laboratory of Veterinary Biochemistry and Molecular Biology, College of Veterinary Medicine, \\ Chungbuk National University, Cheongju, Chungcheongbuk-do 361-763; ${ }^{2}$ Department of Biomaterials Science, \\ College of Natural Resources and Life Science, Pusan National University, Miryang, Pusan 627-706; \\ ${ }^{3}$ SooAm Biotech Research Foundation, Seoul 152-100, Republic of Korea
}

Received February 25, 2013; Accepted June 26, 2013

DOI: $10.3892 / \mathrm{mmr} .2013 .1592$

\begin{abstract}
Metabolic syndrome arises from a combination of disorders that increase the risk of cardiovascular disease and diabetes. In previous studies, it was observed that overexpression of $11 \beta$-hydroxysteroid dehydrogenase type 1 (11 $\beta$-HSD1) induced obesity and the insulin resistance that accompanies metabolic syndrome in rodent adipose tissue. Based on these observations, it was hypothesized that overexpression of $11 \beta$-HSD1 may be suitable for the generation of a porcine model of metabolic syndrome. It was evaluated that promoter activities of the porcine adipose fatty acid-binding protein (aP2) gene generates adipose tissue-specific 11 $\beta$-HSD1 expression. In adipose tissue, the maximum promoter activity $(-2,826$ to $+51 \mathrm{nt}$ ) of aP2 was 200 -fold higher than that of a promoterless construct. In addition, $11 \beta$-HSD1 transcriptional levels were significantly increased following the introduction of the aP2 promoter into 3T3-L1 adipocytes. These observations indicate that the aP2 promoter may facilitate $11 \beta$-HSD1 overexpression in porcine adipose tissue. Transgenic fibroblasts were generated containing $11 \beta-H S D 1$ cDNA controlled by the aP2 promoter with two screening markers, green fluorescence protein and a neomycin-resistance gene. It was hypothesized that transgenic fibroblasts may be useful for generating a porcine model of metabolic syndrome.
\end{abstract}

Correspondence to: Dr Eui-Bae Jeung, Laboratory of Veterinary Biochemistry and Molecular Biology, College of Veterinary Medicine, Chungbuk National University, 12 Gaesin-dong, Cheongju, Chungcheongbuk-do 361-763, Republic of Korea E-mail: ebjeung@chungbuk.ac.kr

Dr Woo-Suk Hwang, SooAm Biotech Research Foundation, 64 Kyunginro, Seoul 152-100, Republic of Korea

E-mail: hwangws@sooam.org

Key words: pig, fibroblast, metabolic syndrome, 11ß-HSD1, aP2 promoter

\section{Introduction}

Metabolic syndrome caused by insulin resistance and abnormal adipose tissue deposition is associated with various risk factors, including coronary artery disease, stroke, fatty liver development and type 2 diabetes $(1,2)$. This syndrome is also known as cardiometabolic syndrome, metabolic syndrome $\mathrm{X}$, syndrome $\mathrm{X}$, insulin resistance syndrome and Reaven's syndrome. The majority of patients with this disorder are older, obese and insulin-resistant, and have a sedentary lifestyle (3). Clinical symptoms of metabolic syndrome include hypertension, hyperglycemia, hypertriglyceridemia, decreased high-density lipoprotein levels, increased triglyceride levels and abdominal obesity $(4,5)$; however, the etiology of this syndrome is not yet clearly understood.

Numerous mouse models, established through spontaneous mutations or genetic modification, have been employed to investigate metabolic syndrome. Leptin-deficient $\left[\mathrm{Lep}^{(\mathrm{ob} / \mathrm{ob})}\right]$ (6), leptin receptor-deficient $\left[\mathrm{LepR}^{(\mathrm{db} / \mathrm{db})}\right]$ (7), lethal yellow agouti ( $\left.\mathrm{A}^{\mathrm{y}} / \mathrm{a}\right)(8)$, melanocortin 3 receptor-deficient (9), melanocortin 4 receptor-deficient (10), low-density lipoprotein receptor-deficient (11) and apolipoprotein E-deficient mice have been generated $(12,13)$. These animal models develop clinical symptoms similar to those observed in humans, including increased obesity and insulin resistance $(14,15)$.

$11 \beta$-hydroxysteroid dehydrogenase type 1 (11 $\beta$-HSD1) is an NADPH-dependent enzyme that is highly expressed in key metabolic tissues, including liver, adipose tissue and the central nervous system (16). In metabolic tissue, including liver and adipose tissue, $11 \beta$-HSD1 converts cortisone into the active hormone, cortisol $(17,18)$. 11 $\beta$-HSD1 transgenic mice develop abdominal obesity, hyperglycemia, insulin resistance, hyperphagia, hyperleptinemia and increased intra-adipose and portal levels, but not systemic corticosterone levels (19). In addition, the adipose tissue of obese humans has been observed to exhibit elevated 11 $\beta$-HSD1 activity (20).

Genetically modified mice are an attractive tool as they are small in size, easy to handle and possess short generation intervals. However, the phenotypic, genetic, physiological 
and anatomical characteristics of mice are not similar to humans. As pigs are physiologically similar to humans (21), in the present study, genetically modified porcine transgenic fibroblasts were produced to induce metabolic syndrome-like symptoms in a porcine model. An 11 $\beta$-HSD1 cDNA construct conjugated to the pig adipose fatty acid-binding protein (aP2) promoter was generated to facilitate $11 \beta-H S D 1$ gene expression in porcine adipose tissue. These transgenic fibroblasts may serve as a source for somatic cell nuclear transfer (SCNT) to produce a porcine model of metabolic syndrome.

\section{Materials and methods}

Cell culture. Mouse embryonic 3T3-L1 fibroblast adipose-like cells were purchased from the Korean Cell Line Bank (Seoul, South Korea). 3T3-L1 preadipocytes were incubated, unless otherwise indicated, at $37^{\circ} \mathrm{C}$ and, unless otherwise indicated, all cell culture materials were obtained from Invitrogen Life Technologies (Carlsbad, CA, USA). On day 30 of pregnancy, porcine fibroblasts were obtained from a miniature pig fetus (Yucatan pig; Optifarm Solution Inc., Gyeonggi-do, South Korea). Fibroblasts were cultured in Dulbecco's modified Eagle's medium (DMEM) containing 10\% fetal bovine serum (FBS; WelGENE, Daegu, South Korea), $50 \mathrm{U} / \mathrm{ml}$ penicillin and $50 \mu \mathrm{g} / \mathrm{ml}$ streptomycin in a humidified $5 \% \mathrm{CO}_{2}$ atmosphere.

Genomic DNA extraction and PCR. Genomic DNA was isolated from the fibroblasts using a G-DEX ${ }^{\mathrm{TM}}$ IIc genomic DNA extraction kit (Intron Biotechnology, Seoul, South Korea). All experimental procedures and animal use were approved by the Ethics Committee of the Chungbuk National University. Genomic DNA ( $1 \mu \mathrm{g})$ was amplified in a $20 \mu \mathrm{l}$ PCR containing 1 unit LA-Taq polymerase (Takara Bio, Inc., Shiga, Japan) for long-range PCR or 1 unit i-star Taq polymerase (Intron Biotechnology), $2 \mathrm{mM}$ dNTPs (Takara Bio, Inc.) and 10 pmol each specific primer. All primers are presented in Table I. PCR conditions were as follows: denaturation at $95^{\circ} \mathrm{C}$ for $30 \mathrm{sec}$, annealing at $62^{\circ} \mathrm{C}$ for $30 \mathrm{sec}$ and extension at $72^{\circ} \mathrm{C}$ for 1 or $2 \mathrm{~min}$. PCR products were separated on a $0.7 \%$ agarose gel, stained with ethidium bromide, imaged under UV illumination and processed for cloning. The gel image was scanned using Gel Doc EQ (Bio-Rad, Hercules, CA, USA).

RNA preparation and semi-quantitative PCR. Total RNA was extracted from 3T3-L1 cells or pig liver (Yucatan pig; Optifarm Solution Inc.) using TRIzol reagent (Invitrogen Life Technologies) according to the manufacturer's instructions. Total RNA concentration was determined by measuring absorbance at $260 \mathrm{~nm}$ (Epoch microplate spectrophotometer; BioTek, Winooski, VT, USA). First strand cDNA was prepared by subjecting total RNA $(1 \mu \mathrm{g})$ to reverse transcription using M-MLV reverse transcriptase (Invitrogen Life Technologies) and random primers (9-mers; Takara Bio Inc.). Optimal conditions for logarithmic phase PCR amplification of the target cDNA were determined by amplifying aliquots of total cDNA $(1 \mu \mathrm{g})$ using a different number of cycles. The cytochrome $c$ oxidase subunit $1(1 \mathrm{~A})$ gene was used as an internal control to eliminate the possibility of RNA degradation and to account for variation in mRNA concentration. A linear correlation between the PCR product band visibility and the number of amplification cycles was observed in the target mRNA products. The 1A gene and target gene, insulin, were quantified using 28 and 30 cycles, respectively. PCR conditions were as follows: denaturation at $95^{\circ} \mathrm{C}$ for $30 \mathrm{sec}$, annealing at $58^{\circ} \mathrm{C}$ for $30 \mathrm{sec}$ and extension at $72^{\circ} \mathrm{C}$ for $30 \mathrm{sec}$. PCR products were separated in a $2.3 \%$ agarose gel, stained with ethidium bromide and imaged under UV illumination. The image was scanned and band densities were analyzed using Gel Doc EQ (Bio-Rad).

Vector construction. Restriction enzymes were obtained from Takara Bio, Inc. Specific regions of the aP2 promoter were prepared by long-range PCR using porcine genomic DNA as a template and specific primers containing restriction enzyme sites (MluI at $5^{\prime}$ end or $B g l I I$ at $3^{\prime}$ end). Amplified fragments were digested with $M l u \mathrm{I}$ and $B g l \mathrm{II}$ and ligated into the promoterless pGL3-Basic luciferase expression plasmid (Promega Corporation, Madison, WI, USA). The $11 \beta-H S D 1$ expression cassette plasmid was produced in several steps. 11 $\beta-H S D 1$ cDNA was prepared by PCR using cDNA from pig liver as a template. The amplified fragments were inserted into the recombinant pGL3 construct containing the pig aP2 promoter region $(-2,826$ to $+51 \mathrm{nt})$. For the selection cassettes, the enhanced green fluorescent protein (EGFP) gene was amplified from the pIRES2-EGFP plasmid (Clontech Laboratories Inc., Mountain View, CA, USA), digested with EcoRV and BamHI and inserted into the pIRESneo plasmid (Clontech Laboratories Inc.). The EGFP and neomycin-resistant (Neor) genes were amplified by PCR, digested with SalI and ligated into the recombinant pGL3 vector encoding pig $11 \beta$-HSD1 cDNA controlled by the porcine aP2 promoter. Finally, sequences of the targeting vector were confirmed by nucleotide sequencing (Genotech Corporation, Daejeon, South Korea).

Transient transfection and reporter gene assay. Transient transfection was performed using Lipofectamine ${ }^{\mathrm{TM}} 2000$ (Invitrogen Life Technologies) according to the manufacturer's instructions. To account for varied transfection efficiencies of the various luciferase constructs, the Rous sarcoma virus (RSV)-lacZ plasmid was co-transfected with the luciferase constructs containing the pig aP2 promoter, as previously described $(22,23)$. Briefly, $3 \times 10^{5}$ cells were seeded in 6-well tissue culture plates (Invitrogen Life Technologies) $1 \mathrm{~d}$ prior to transfection. Constructs $(4 \mu \mathrm{g})$ containing the aP2 promoter and RSV-lacZ plasmid $(0.5 \mu \mathrm{g})$ were co-transfected into the cells with DMEM. Following an incubation period of $4 \mathrm{~h}$, the media was replaced with DMEM containing 10\% FBS and glucose $(0.1$ or $4 \mathrm{mM})$ and the cells were incubated for an additional $48 \mathrm{~h}$ at $37^{\circ} \mathrm{C}$. Cell lysates were assayed for luciferase activity using a luciferase assay system (Promega Corporation). Luminescence was measured using a GloMax 20/20 Luminometer (Promega Corporation). $\beta$-galactosidase activity was measured using a $\beta$-galactosidase enzyme assay system (Promega Corporation). Relative luciferase activity was calculated as luciferase activity/ $\beta$-galactosidase activity (\%).

Establishment of transgenic cell lines. Porcine fibroblasts were transfected with the linearized targeting vector using Lipofectamine 2000. Following $24 \mathrm{~h}$ transfection, the medium was replaced with DMEM supplemented with 10\% FBS and $250 \mu \mathrm{g} / \mathrm{ml}$ G-418 (Roche Diagnostics, Indianapolis, IN, USA) 
Table I. Primer sequences and restriction enzymes.

\begin{tabular}{llll}
\hline Name & Restriction enzyme & Direction & \\
\hline Pig aP2 promoter $(-4,424)$ & $M l u \mathrm{I}$ & Forward & ACGCGTTATGGGAAGTATGTTTTGGA \\
Pig aP2 promoter $(-2,826)$ & $M l u \mathrm{I}$ & Forward & ACGCGTGGACTTTAATGGACACCTCACC \\
Pig aP2 promoter $(-658)$ & $M l u \mathrm{I}$ & Forward & ACGCGTTACAACCCAACAGCAAAA AAGCC \\
Pig aP2 promoter $(+51)$ & XhoI & Reverse & CTCGAGCCTTCAGGAAGGTGCAATGAC \\
Pig 11 $\beta$-HSD cDNA & BglII & Forward & AGATCTATGGCTTTTATGAAAAAATATCTCCTCC \\
Pig 11 $\beta$-HSD cDNA & XbaI & Reverse & TCTAGACTAGTTGTTTGTAACCTTTCCATATTA \\
EGFP cDNA & EcoRV & Forward & GATATCCACAACCATGGTGAGCAAGGGCGA \\
EGFP cDNA & BamHI & Reverse & GGATCCTTACTTGTACAGCTCGTCCATGCC \\
Confirming primer a & & Forward & CCATGATAATAAGCCTGCTCTACTCCA \\
Confirming primer b & & Reverse & GGAAGTCATGAAGGCCTGGGTGATG \\
Confirming primer c & & Forward & CATGAAGCAGCACGACTTCT \\
Confirming primer d & & Reverse & CCTAGGAATGCTCGTCAAGA \\
1A & & Forward & CCAGGATTTGGAATTATTC \\
1A & & Reverse & GAAAATAAAGCCTAAGGCTC \\
Pig 11 $\beta$-HSD & & Forward & CAACGTGTCAATCACGCTCT \\
Pig 11 $\beta$-HSD & & Reverse & TTCCTGGATTTTCCAACAGG
\end{tabular}

11ß-HSD1, 11ß-hydroxysteroid dehydrogenase type 1; EGFP, enhanced green fluorescent; $1 \mathrm{~A}, \mathrm{c}$ the ytochrome $c$ oxidase subunit.

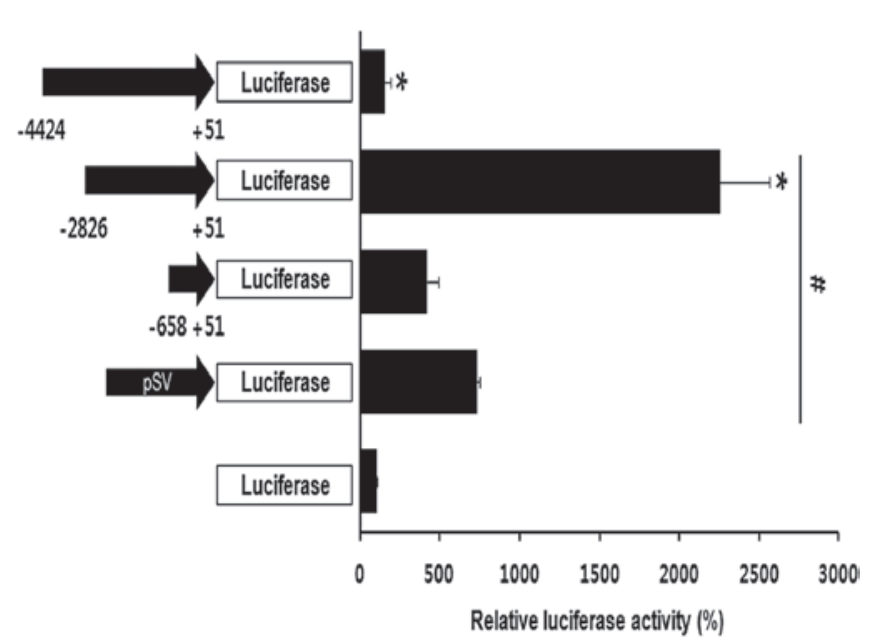

Figure 1. Luciferase reporter gene assay to evaluate aP2 gene promoter activity following transient transfection. 3T3-L1 cells were transiently transfected with designated constructs. Cells were co-transfected with a RSV-lacZ expression vector to normalize transfection efficiency. RLU was calculated as a percentage of the simian virus 40 promoter (pSV plasmid) RLU, which was set at $100 \%$. Data are expressed as the mean \pm SEM of three independent experiments conducted in triplicate. ${ }^{*} \mathrm{P}<0.05$ vs. RLU of the promoterless plasmid; " $\mathrm{P}<0.05$ vs. $\mathrm{RLU}$ of the -658 to $+51 \mathrm{nt}$ aP 2 promoter. $\mathrm{RLU}$, relative luciferase activity.

for 4 weeks. Antibiotic-resistant colonies were further selected according to EGFP expression observed with a fluorescence microscope (Nikon, Tokyo, Japan). Antibiotic and visually selected colonies were subjected to PCR-based genotyping and stored until required for SCNT.

Statistical analysis. Data are presented as the mean \pm SEM. A statistical analysis was performed by Student's t-test for
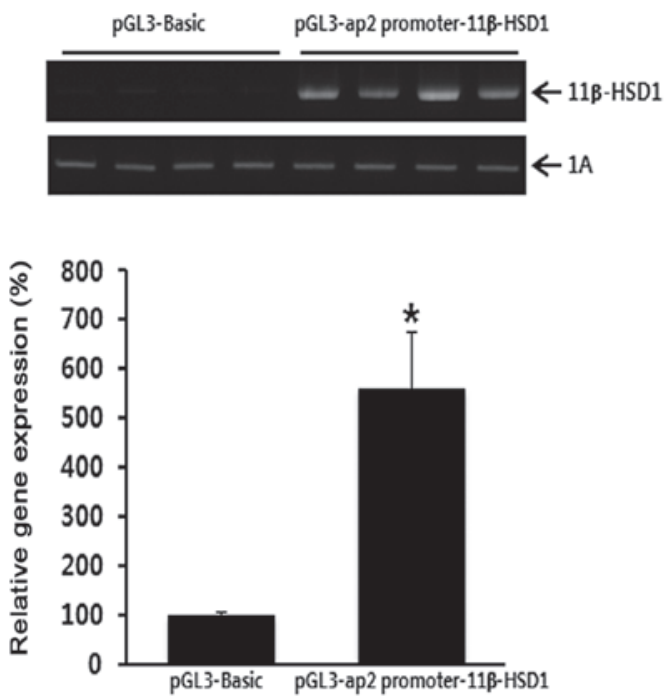

Figure 2. Overexpression of recombinant porcine 11 $\beta$-HSD1 in 3T3-L1 cells. 3T3-L1 cells were transfected with the porcine 11 $\beta$-HSD1 expression constructs containing the pig aP2 promoter. 11 $\beta$-HSD1 mRNA expression was measured by semi-quantitative PCR. 11 $\beta$-HSD1 mRNA expression was normalized against expression of the $1 \mathrm{~A}$ gene as an internal control. ${ }^{*} \mathrm{P}<0.05$ vs. the promoterless pGL3-basic. $11 \beta$-HSD1, 11 $\beta$-hydroxysteroid dehydrogenase type $1 ; 1 \mathrm{~A}$, cytochrome $c$ oxidase subunit 1 .

two-pair comparisons. $\mathrm{P}<0.05$ was considered to indicate a statistically significant difference.

\section{Results}

Functional analysis of the pig aP2 promoter. Prior to the generation of the $11 \beta$-HSD1 cDNA construct, a pig aP2 promoter that was hypothesized to be activated in adipocytes 
Table II. Transfection efficiencies of the pig fibroblasts.

\begin{tabular}{|c|c|c|c|}
\hline Transfection trials, $\mathrm{n}$ & $\begin{array}{c}\text { G418-resistant } \\
\text { colonies, } n\end{array}$ & $\begin{array}{l}\text { EGFP-positive } \\
\text { colonies, } \mathrm{n}\end{array}$ & $\begin{array}{l}\text { PCR-positive } \\
\text { colonies, } \mathrm{n}\end{array}$ \\
\hline 11 & 37 & 33 & 33 \\
\hline
\end{tabular}

A

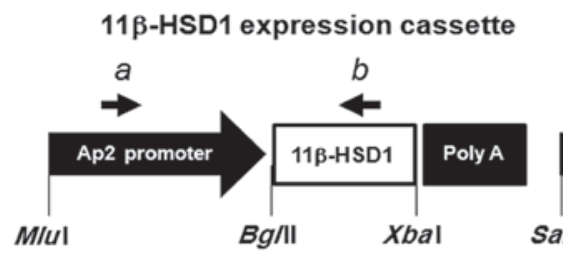

B
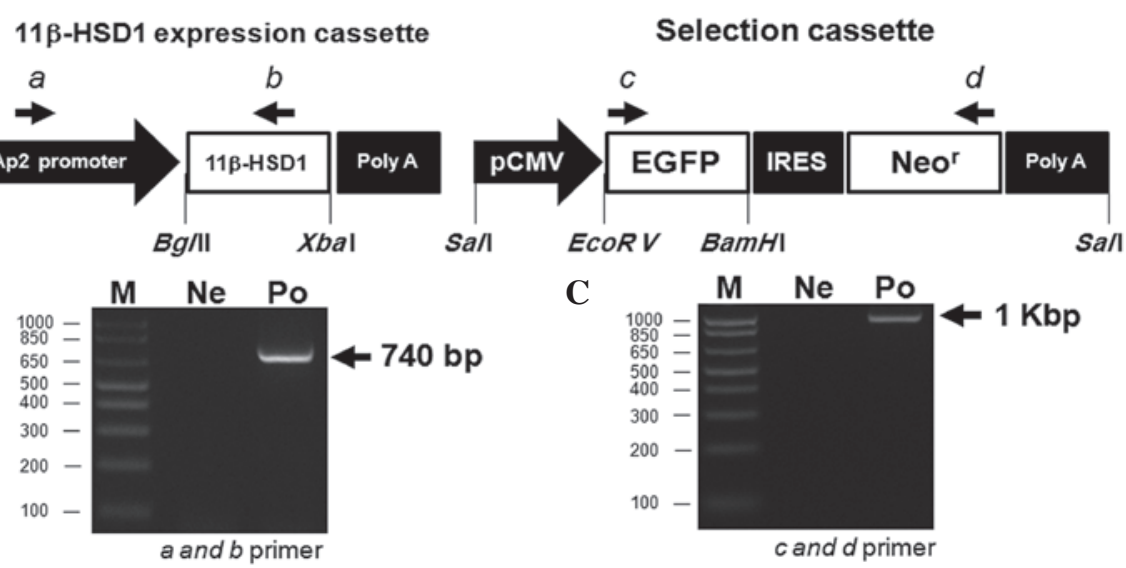

Figure 3. Schematic representation of constructs and PCR-based confirmation of the transgenic fibroblast identity. (A) $11 \beta$-HSD1 expression cassettes included an 11ß-HSD1 gene with the aP2 promoter. The selection cassette contained EGFP and Neor genes linked by an IRES sequences. Integration of the constructs into fibroblast genomic DNA was confirmed by PCR using specific primers as indicated by the arrows. (B) Chromosomal insertion of the 11ß-HSD1 expression cassettes was confirmed by PCR. (C) Transgenic fibroblasts containing the selection cassette were identified by PCR using specific primers. M, molecular marker; Ne, negative control without template; Po, a positive colony expressing the EGFP and Neor selection markers; EGFP, enhanced green fluorescent; Neor, protein neomycin resistant; 11 $\beta$-HSD1, 11 $\beta$-hydroxysteroid dehydrogenase type 1.

A

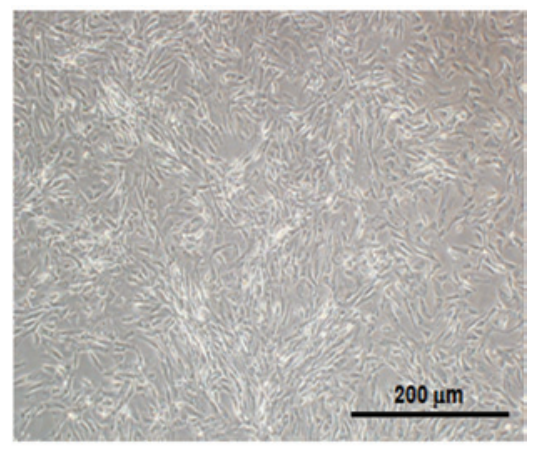

B

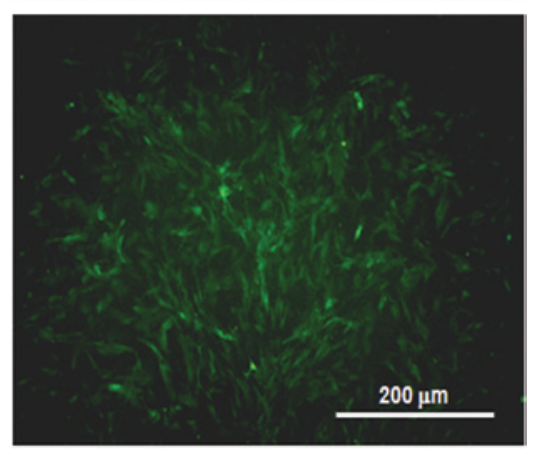

Figure 4. Morphology of the transgenic fibroblasts. Fetal porcine fibroblasts were transfected with targeting constructs using a liposomal-mediated gene delivery system and incubated with G-418 for 4 weeks. Fibroblasts stably expressing 11 $\beta$-HSD1 were successfully produced. (A) G418-resistant cells were examined under light microscopy (magnification, x40) (B) EGFP expression was observed with fluorescent microscopy (magnification, $\mathrm{x} 40$ ). EGFP enhanced green fluorescent; Neor, protein neomycin resistant; 11 $\beta$-HSD1, 11 $\beta$-hydroxysteroid dehydrogenase type 1. was produced. The aP2 gene is typically expressed in adipose tissue and the maximum promoter activity of aP2 in the adipose tissue was previously confirmed (24). A series of pig aP2 gene promoters with sequential deletions were inserted into the luciferase (Luc) gene in a promoterless pGL3-basic vector. The aP2 promoter constructs were introduced into the mouse embryonic fibroblast-adipose 3T3-L1 cells and the promoter activities were evaluated according to Luc expression. As presented in Fig. 1, the promoter region between -2,826 and +15 nt resulted in an $\sim 20$-fold increase of Luc activity compared with the promoterless construct. These observations indicate that $-2,826$ to $+15 \mathrm{nt}$ of the $\mathrm{aP} 2$ promoter was the best candidate adipocyte-specific expression promoter.

Overexpression of recombinant pig $11 \beta-H S D 1$ in 3T3-L1 cells. Following verification that the aP2 promoter construct containing $-2,826$ to $+15 \mathrm{nt}$ had maximal activity, the construct was subcloned with porcine $11 \beta-H S D 1$ cDNA. The resulting aP2/11 $\beta$-HSD1 construct was capable of expressing $11 \beta$-HSD1 mRNA in an adipocyte-specific manner. 11 $\beta$-HSD1 mRNA levels increased in the transiently-transfected 3T3-L1 cells (Fig. 2). These observations indicate that the recombinant aP2/11/-HSD1 construct was appropriate for expressing pig $11 \beta-H S D 1$ in an adipose tissue-specific manner.

Establishment of porcine fibroblast cell lines that overexpress $11 \beta-H S D 1$. Our constructs were composed of two parts, an 11 $\beta$-HSD1 expression cassette and a selection cassette (Fig. 3A). 
The 11 $\beta$-HSD1 expression cassette contained pig 11 $\beta$-HSD1 cDNA with the porcine aP 2 promoter region $(-2,826$ to $+15 \mathrm{nt})$. The selection cassette contained EGFP and Neor genes, whose expression was regulated by a cytomegalic virus promoter. Expression of the EGFP and Neor genes enabled selection of the cells of interest using antibiotics and visual screening.

The targeting construct was linearized and used to transfect porcine fibroblasts isolated from Yucatan pigs. Fibroblasts were incubated in medium containing G-418 $(250 \mu \mathrm{g} / \mathrm{ml})$ for 4 weeks to select for the stable transfectants. Identification of Neor colonies as transgenic fibroblasts was confirmed by EGFP expression (Fig. 4). The clones were further identified by PCR-based methods using primers specific for the targeting constructs. Genomic DNA from clones expressing porcine $11 \beta$-HSD1 was analyzed with an a-b primer set (amplicon size, 740 bp; Fig. 3B) or with c-d primers (amplicon size, $1 \mathrm{~kb}$; Fig. 3C). Transfection efficiency was $\sim 89 \%$ (Table II). These observations indicate that the cell model may be useful for establishing a transgenic fibroblast system for creating porcine metabolic syndrome models by expressing adipose tissue-specific 11 $\beta$-HSD1.

\section{Discussion}

Tissue-specific promoters generally contain cis-acting elements to which tissue-specific transcription factors bind and regulate tissue-specific expression of genes. Fatty acid-binding proteins are an intracellular hydrophobic ligand-binding protein family (25). aP2 (also known as fatty acid-binding protein 4) facilitates the intracellular solubilization and trafficking of lipids (26). This factor has been implicated as a strong candidate for adipose-specific genes representing the accumulation of lipids in pigs and cows $(27,28)$. Previously, the aP2 promoter in humans and mice was analyzed to identify fat-specific regulatory regions (29). This promoter contains conserved transcription factor binding sites, including $\mathrm{C} / \mathrm{EBP}$, adapter primer-1, CAAT box, TATA box, direct repeat 1-type PPAR responsive element, short interspersed repetitive elements and another PPAR responsive element in humans, mice, cows, pigs and dogs (24). The $-5.4 \mathrm{~kb}$ region upstream of the aP 2 promoter is hypothesized to direct the adipose-specific expression of transgenes in mice (30). The aP2 promoter was utilized to overexpress $11 \beta$-HSD1 in adipose tissue. Activity of the porcine aP2 promoter in the 3T3-L1 adipose cells was examined. A specific portion of the porcine aP2 promoter (between $-2,826$ and $+15 \mathrm{nt}$ ) was observed to possess the highest activity among the various tested promoter regions.

The $11 \beta$-HSD1 gene is highly expressed in the adipose tissue of obese humans (20). In the present study, a porcine fibroblast cell line was established expressing the pig $11 \beta$-HSD1 gene under the control of the porcine aP2 promoter. In addition, two selection markers, EGFP and the Neor gene, were used for genetic information of somatic cells for further SCNT-mediated cloning. The Neor and EGFP genes are used to select transgenic cell colonies to increase SCNT efficiency and identify transgenic piglets (31-33). Therefore, the use of these porcine fibroblasts cells is likely to enable us to achieve high somatic cell cloning efficiencies in mammals.

Although there are several animal models of metabolic syndrome, the majority are rodents, including mice and rats, which are relatively dissimilar to humans. A porcine model of metabolic syndrome has several advantages, including the physiological similarity between pigs and humans in terms of body fat distribution and fat cell size. Therefore, insight into lipogenesis, lipolysis and lipid mobilization gained from evaluating a porcine model may be useful for studying human obesity. In addition, numerous diagnostic and surgical techniques developed for humans are applicable in pigs, further indicating that the pig is a valuable model for investigating various human diseases.

In conclusion, a porcine fibroblast cell line containing constructs suitable for $11 \beta$-HSD1 overexpression was established. To assess adipose-specific expression of the 11 $\beta$-HSD1 gene, an aP2 promoter controlling expression in adipose tissue was included in the construct. These porcine fibroblast cell lines may be a useful source for SCNT procedures to generate a porcine model of metabolic syndrome. Piglets derived from these cells may also provide critical information for understanding the pathophysiology of metabolic syndrome and developing novel diagnostic therapies for combating human metabolic syndrome.

\section{Acknowledgements}

This study was supported by a grant from the Next-Generation BioGreen 21 Program (no. PJ009563), Rural Development Administration, Republic of Korea.

\section{Reference}

1. Olufadi R and Byrne CD: Clinical and laboratory diagnosis of the metabolic syndrome. J Clin Pathol 61: 697-706, 2008.

2. Rask-Madsen C and Kahn CR: Tissue-specific insulin signaling, metabolic syndrome and cardiovascular disease. Arterioscler Thromb Vasc Biol 32: 2052-2059, 2012.

3. Grundy SM, Brewer HB Jr, Cleeman JI, Smith SC Jr and Lenfant C; National Heart, Lung and Blood Institute; American Heart Association: Definition of metabolic syndrome: report of the National Heart, Lung and Blood Institute/American Heart Association conference on scientific issues related to definition. Arterioscler Thromb Vasc Biol 24: e13-e18, 2004.

4. Roos CJ, Quax PH and Jukema JW: Cardiovascular metabolic syndrome: mediators involved in the pathophysiology from obesity to coronary heart disease. Biomark Med 6: 35-52, 2012.

5. Vogelzangs N and Penninx BW: Depressive symptoms, cortisol, visceral fat and metabolic syndrome. Tijdschr Psychiatr 53: 613-620, 2011 (In Dutch).

6. Nishina PM, Lowe S, Wang J and Paigen B: Characterization of plasma lipids in genetically obese mice: the mutants obese, diabetes, fat, tubby and lethal yellow. Metabolism 43: 549-553, 1994.

7. Hummel KP, Dickie MM and Coleman DL: Diabetes, a new mutation in the mouse. Science 153: 1127-1128, 1966.

8. Tschöp M and Heiman ML: Rodent obesity models: an overview. Exp Clin Endocrinol Diabetes 109: 307-319, 2001.

9. Trevaskis JL, Gawronska-Kozak B, Sutton GM, et al: Role of adiponectin and inflammation in insulin resistance of $\mathrm{Mc} 3 \mathrm{r}$ and Mc4r knockout mice. Obesity (Silver Spring) 15: 2664-2672, 2007.

10. Tallam LS, Stec DE, Willis MA, da Silva AA and Hall JE: Melanocortin-4 receptor-deficient mice are not hypertensive or salt-sensitive despite obesity, hyperinsulinemia and hyperleptinemia. Hypertension 46: 326-332, 2005

11. Ishibashi S, Brown MS, Goldstein JL, Gerard RD, Hammer RE and Herz J: Hypercholesterolemia in low density lipoprotein receptor knockout mice and its reversal by adenovirus-mediated gene delivery. J Clin Invest 92: 883-893, 1993.

12. Plump AS, Smith JD, Hayek T, et al: Severe hypercholesterolemia and atherosclerosis in apolipoprotein E-deficient mice created by homologous recombination in ES cells. Cell 71: 343-353, 1992. 
13. Zhang SH, Reddick RL, Piedrahita JA and Maeda N: Spontaneous hypercholesterolemia and arterial lesions in mice lacking apolipoprotein E. Science 258: 468-471, 1992.

14. Kennedy AJ, Ellacott KL, King VL and Hasty AH: Mouse models of the metabolic syndrome. Dis Model Mech 3: 156-166, 2010.

15. Asterholm IW, Halberg N and Scherer PE: Mouse Models of Lipodystrophy Key reagents for the understanding of the metabolic syndrome. Drug Discov Today Dis Models 4: 17-24, 2007.

16. Agarwal AK: Cortisol metabolism and visceral obesity: role of 11beta-hydroxysteroid dehydrogenase type I enzyme and reduced co-factor NADPH. Endocr Res 29: 411-418, 2003.

17. White PC, Mune T and Agarwal AK: 11 beta-Hydroxysteroid dehydrogenase and the syndrome of apparent mineralocorticoid excess. Endocr Rev 18: 135-156, 1997.

18. White PC, Mune T, Rogerson FM, Kayes KM and Agarwal AK Molecular analysis of 11 beta-hydroxysteroid dehydrogenase and its role in the syndrome of apparent mineralocorticoid excess. Steroids 62: 83-88, 1997.

19. Masuzaki H, Paterson J, Shinyama H, et al: A transgenic model of visceral obesity and the metabolic syndrome. Science 294 2166-2170, 2001

20. Rask E, Olsson T, Söderberg S, et al: Tissue-specific dysregulation of cortisol metabolism in human obesity. J Clin Endocrinol Metab 86: 1418-1421, 2001

21. Groth CG: Xenotransplantation is the hope of the future. Genetic modification of the donor, the pig, is better than fighting organ rejection by submitting patients to immunosuppression with frequent side effect. Lakartidningen 99: 252-254, 2002 (In Swedish).

22. Cheng CK, Hoo RL, Chow BK and Leung PC: Functional cooperation between multiple regulatory elements in the untranslated exon 1 stimulates the basal transcription of the human GnRH-II gene. Mol Endocrinol 17: 1175-1191, 2003.

23. Lee GS, Choi KC, Han HJ and Jeung EB: The classical and a non-classical pathways associated with NF-kappaB are involved in estrogen-mediated regulation of calbindin-D9k gene in rat pituitary cells. Mol Cell Endocrinol 277: 42-50, 2007.
24. Shin J, Li B, Davis ME, Suh Y and Lee K: Comparative analysis of fatty acid-binding protein 4 promoters: conservation of peroxisome proliferator-activated receptor binding sites. J Anim Sci 87: 3923-3934, 2009.

25. Xu Z, Bernlohr DA and Banaszak LJ: Crystal structure of recombinant murine adipocyte lipid-binding protein. Biochemistry 31 : 3484-3492, 1992.

26. Thompson BR, Mazurkiewicz-Muñoz AM, Suttles J, Carter-Su C and Bernlohr DA: Interaction of adipocyte fatty acid-binding protein (AFABP) and JAK2: AFABP/aP2 as a regulator of JAK2 signaling. J Biol Chem 284: 13473-13480, 2009.

27. Estellé J, Perez-Enciso M, Mercadé A, et al: Characterization of the porcine FABP5 gene and its association with the FAT1 QTL in an Iberian by Landrace cross. Anim Genet 37: 589-591, 2006.

28. Wibowo TA, Gaskins CT, Newberry RC, Thorgaard GH, Michal JJ and Jiang Z: Genome assembly anchored QTL map of bovine chromosome 14. Int J Biol Sci 4: 406-414, 2008.

29. Rival Y, Stennevin A, Puech L, et al: Human adipocyte fatty acid-binding protein (aP2) gene promoter-driven reporter assay discriminates nonlipogenic peroxisome proliferator-activated receptor gamma ligands. J Pharmacol Exp Ther 311: 467-475, 2004.

30. Ross SR, Graves RA, Greenstein A, et al: A fat-specific enhancer is the primary determinant of gene expression for adipocyte P2 in vivo. Proc Natl Acad Sci USA 87: 9590-9594, 1990.

31. Jung EM, Kim YK, Lee GS, Hyun SH, Hwang WS and Jeung EB: Establishment of inducible cAMP early repressor transgenic fibroblasts in a porcine model of human type 1 diabetes mellitus. Mol Med Rep 6: 239-245, 2012.

32. Kim YK, Lee GS, Jung EM, Hyun SH, Hwang WS and Jeung EB: Generation of fibroblasts overexpressing liver-specific PEPCK in a miniature pig model of human type 2 diabetes mellitus. Mol Med Rep 6: 45-50, 2012.

33. Lee GS, Hyun SH, Kim HS, et al: Improvement of a porcine somatic cell nuclear transfer technique by optimizing donor cell and recipient oocyte preparations. Theriogenology 59: 1949-1957, 2003. 